\title{
Spatial and Temporal Parameters of the Trapped Waves in the Black Sea Shelf Areas
}

\author{
V. A. Ivanov, T. Ya. Shul'ga*, T. V. Plastun, I. A. Svishcheva \\ Marine Hydrophysical Institute, Russian Academy of Sciences, Sevastopol, Russian Federation \\ *e-mail: shulgaty@mail.ru
}

The mechanism of generating barotropic long waves on the Black Sea Turkish coast is studied. Influence of the shelf shape and width upon the spatial-temporal parameters of the edge waves' lower modes is noted based on solution of the complete boundary-value problem using the developed algorithms of the finite-difference approximation. To simulate the generated on the Anatolian coast waves induced by the climatic wind, the three-dimensional model (for the Black and Azov seas) of the Institute of Numerical Mathematics of RAS is used. Position of the wave attenuation points and maximums of the level oscillations' amplitudes depending on the topography feature in the boundary area (the shelf and the continental slope zone) are studied. It is shown that the profile absolute maximum of the first mode wave is achieved at the coast and above the shelf edge. Increase of the continental slope width leads to slower decay of a wave towards the open sea. Convergence of the dispersion curves at high frequencies for various widths of the shelf is demonstrated. At the intermediate frequencies on the wide shelf, the dispersion curves are horizontal and their group velocity is close to zero. Having been studied, the spatial-temporal characteristics of the edge waves at real bottom profiles show that the waves with the longest periods arise in the region of the Ince Burnu that is due to manifestation of the zero mode of the trapped edge waves. The graphs of the dispersion curves and the maps of the amplitude functions of the shelf modes are constructed for the Anatolian coast. The model time series of the sea level are analyzed to calculate spectral density of the water level oscillations' power at the coast using the fast Fourier transformation. The spectra of the level oscillations' amplitudes for the shelf and deep sea stations of the Anatolian coast are represented.

Keywords: Anatolian coast, Black Sea, phase velocity, shelf, barotropic trapped waves, continental slope, hydrodynamic modeling, spectral analysis.

Acknowledgements: the authors express their thanks to Professor Aleksandr E. Yankovsky (former scientist of the Marine Hydrophysical Istitute and at present an employee at the University of South Carolina (Columbia, USA)) for his support of the present research and consultations in creating the applications for processing information on the intra-wave oscillations. The study is carried out within the framework of the state task on the theme No. 0827-2018-0004 "Complex interdisciplinary investigations of the oceanologic processes conditioning functioning and evolution of the Black and Azov seas' coastal zones" (code "Coastal investigations").

For citation: Ivanov, V. A., Shul'ga, T. Ya., Plastun, T. V. and Svishcheva, I. A., 2018. Spatial and Temporal Parameters of the Trapped Waves in the Black Sea Shelf Areas. Physical Oceanography [e-journal] 25(4), pp. 280-294. doi:10.22449/1573-160X-2018-4-280-294

DOI: 10.22449/1573-160X-2018-4-280-294

(c) 2018, V. A. Ivanov, T. Ya. Shul'ga, T. V. Plastun, I. A. Svishcheva

(C) 2018, Physical Oceanography

\section{Introduction}

Long waves determine the character of the most hydrophysical processes occurring in marine basins or at their boundaries, including the formation of coastal area relief, upwelling, meandering of currents, biological productivity change. In the topographically boundary areas formed by the relief change and the presence of a shore (shelf zone, submarine ridges, troughs, banks) the depth variations lead to 
the formation of horizontally inhomogeneous waves, as well as to the occurrence of boundary wave formations (surface and internal Kelvin waves, edge and shelf waves, double Kelvin waves, bottom trapped waves) [1-4]. There are three main types of trapped waves for the barotropic motions: Kelvin wave (capture by the Earth rotation and the presence of coastal boundary); edge waves (gravitational capture in the shallow water area); topographic Rossby waves (capture by the joint effect of the Earth rotation and relief inhomogeneity) [5]. According to the contemporary concept, they play an important role in numerous processes of coastal dynamics (such as the transport of sedimentary material, surf beats) and are often considered as determining factors in the shoreline evolution at the formation of rhythmic forms of relief (sickle-shaped bars and festoons). Large-scale edge waves are an important component of sea waves and floods caused by cyclones moving along the shoreline.

Kelvin's eigenwave existing at the frequencies which are both higher and lower than the inertial one is described by analytical solution that assumes a rotating ocean with a constant depth [6] bounded by a vertical wall. The features of this solution are well-known: constant phase velocity $c=(g h)^{1 / 2}$ (where $g$ - is a free fall acceleration, $h$ - is a depth of the basin), free surface exponential attenuation at the shelf, wave propagation on the right (left) from the coast in the Northern (Southern) hemisphere. At low frequencies the character of Kelvin wave is determined by the Earth rotation. With the frequency increase the shelf zone begins to exert a growing impact as a result of which the Kelvin wave shifts to zero mode of edge waves $[3,4,7]$. At high frequencies zero mode shifts to edge wave, coastal capture takes place through the mechanism of refraction of a long gravitational wave, while the Earth rotation effects become insignificant.

The purpose of this work is to study the parameters of shelf waves in topographically boundary areas - at the shelf and continental slope. The bottom relief effect on the spatial-temporal parameters of the shelf wave lower modes near the critical frequency is determined using the example of the real profiles of the Anatolian coast bottom and idealized profiles indicating the characteristic linear scales of the Black Sea basin shelf regions.

\section{Theoretical estimates of trapped wave parameters}

We consider how the zero mode parameters vary depending on geometry of shelf and slope. The study of topographically modified waves is carried out using the model with simple geometry in which the parameters of the considered area depend only on one spatial variable. In this case the solution of the problem about the spreading of long waves in the ocean is simplified. In the selected coordinate system $x$-axis coincides with the shoreline, $y$-axis is directed towards the open sea (Fig. 1).

Mathematical model is based on the system of linear equations in hydrostatic approximation (long wave approximation) for non-viscous liquid of uniform density rotating with a constant angular velocity:

$$
\frac{\partial u}{\partial t}-f v=-g \frac{\partial \zeta}{\partial x},
$$




$$
\begin{gathered}
\frac{\partial v}{\partial t}+f u=-g \frac{\partial \zeta}{\partial y}, \\
\frac{\partial \zeta}{\partial t}=-\frac{\partial(h u)}{\partial x}-\frac{\partial(h v)}{\partial y},
\end{gathered}
$$

where $x$ is an alongcoast coordinate; $y$ is a coordinate transverse to the shore; $t$ is a time; $h(y)$ is the sea depth; $u(x, y, t)$ and $v(x, y, t)$ are the coastal and marine velocity components, respectively; $\zeta(x, y, t)$ is a free surface perturbed from the horizontal plane; $f$ is Coriolis parameter.

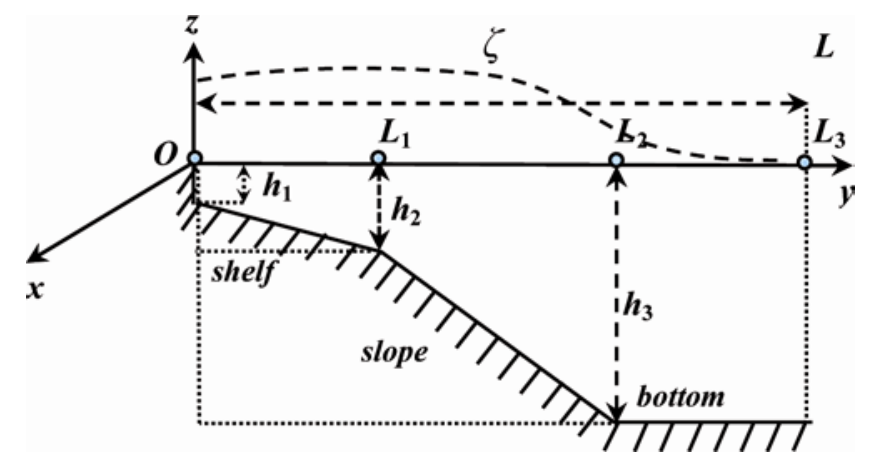

Fig. 1. Model of the bottom profile for test calculations

The depth varies by the normal towards the shore, and then periodic wave-type solution depends only on the alongcoast coordinate and time:

$$
\left(\begin{array}{l}
\zeta(x, y, t) \\
u(x, y, t) \\
v(x, y, t)
\end{array}\right)=\left(\begin{array}{c}
\zeta^{*}(y) \\
u^{*}(y) \\
v^{*}(y)
\end{array}\right) e^{i(\omega t-k x)},
$$

here $k$ is a wave number; $\omega$ is a wave frequency. These assumptions provide a well-known boundary value problem [1, 8-10] describing the entire set of barotropic trapped modes in the coastal regions of the ocean. Solving the equations (1), (2) for $u, v$ and substituting the results in (3) we will obtain a differential equation with regard to the required oscillation amplitude of $\zeta(y$ ) level (for convenience, the asterisks are omitted):

$$
\frac{\partial^{2} \zeta(y)}{\partial y^{2}}+\frac{\partial \zeta(y)}{\partial y} \frac{\partial h(y)}{\partial y} \frac{1}{h(y)}+\zeta(y)\left(\frac{f^{2}-\omega^{2}}{g h(y)}-\frac{f k}{\omega} \frac{1}{h(y)} \frac{\partial h(y)}{\partial y}-k^{2}\right)=0
$$

with the corresponding boundary conditions of the absence of normal component of full flux through the coastal boundaries and exponential decay of perturbations towards the open sea by $H(y \rightarrow \infty)$ depth:

$$
v=0, \quad y=0, \quad \omega \frac{\partial \zeta(y)}{\partial y}-k f \zeta(y)=0, \quad h(0) \neq 0
$$


In (5), (6) $h=h(y)$ is a sea depth profile varying only in the transverse direction. Wave solutions for this boundary value problem and their features are discussed in detail in $[1,7,10]$. At $\omega^{2}<f^{2}+k^{2} g H$, wave solution of boundary value problem exponentially decays towards the open sea and is a discrete set of individual modes of trapped waves. The waves of this type becomes the boundary ones at $\omega>f$ and shelf ones - at $\omega<f$.

Spatial and temporal boundary wave characteristics calculated for the bottom test profiles. In order to determine the contribution of the sections of boundary area relief (the shelf and the continental slope), the calculations with the use of $h(y)$ depth profiles consisting of three piecewise constant inclinations: a shelf, a slope and an open sea area of constant depth. The details of the bottom relief are shown in Fig. 1. Within the shelf and continental slope limits the depth linearly increases and the bottom slope changes in an abrupt way at the shelf edge. In all cases linear scales of topography are the following: the depth near the shore $\left(h_{1}\right)$, the shelf edge depth $\left(h_{2}\right)$, the open sea depth $\left(h_{3}=H\right)$, the shelf width $\left(L_{1}\right)$, the continental slope width $\left(L_{2}\right)$ and the foot width $\left(L_{3}\right)$. The relief of continental shelf and slope is approximated by two slopes adjacent to the deep ocean of constant depth (Fig. 1). Profile depth is characterized by the shelf width as well as by intermediate depth at the intervals between the shelf break points. Side wall, which is a boundary with the coastal zone, is assumed to be equal to $5 \mathrm{~m}$.

For solving the boundary value problem (5), (6) we replace the derivatives by their finite-difference approximations using the central differences in (5) and the one-sided differences in (6). The eigenvalue problem (1) - (3) is solved numerically using the resonance iterations by the spectral parameter $M\left(\mathrm{~m}^{-1}\right)$ equal to $f k / \omega$. The solution corresponds to the finding the points of intersections of constant phase rate $c_{f}=\omega / k=f / M$ lines with dispersion curves of the captured wave modes. The regime number is identified by the amount of zero intersections in the mode structure (eigenvector). The calculations are repeated at different values of $M$. Spatial discretization by $y\left(\Delta_{y}\right)$ is set to be equal to $1 \mathrm{~km}$ in the finite-difference approximation. Coriolis parameter corresponding to the considered area of the Black Sea coast is assumed to be $1.01 \cdot 10^{-4} \mathrm{~s}^{-1}$.

In order to determine the impact of geometry of the main relief sections on the shelf wave parameters the calculations of two groups of bottom testing profiles was carried out. In the first group the fixed slope width and changing shelf width are set, in the second one - the fixed shelf width and the changing slope width. These experiments are performed at constant values of depth profile: $h_{1}=5 \mathrm{~m}, h_{2}=$ $=100 \mathrm{~m}, h_{3}=2000 \mathrm{~m}$. In the first experiment the calculations were carried out for two values of the slope width $\left(L_{2}\right) 100$ and $200 \mathrm{~km}$ at changing shelf width шельфа $\left(L_{1}\right)$ 50, 100, 200 and $300 \mathrm{~km}$. In the second experiment for the shelf with 50 and $100 \mathrm{~m}$ width the increase of slope width from 100 to $200 \mathrm{~km}$ was studied. The results of calculations for the test profiles with the mentioned geometrical dimensions are given in Fig. 2.

Our study shows that the dispersion curve of zero mode is more sensitive to the variations of shelf width $L_{1}$ than to the slope width $L_{2}$. Dispersion diagram of zero mode depends on the shelf width (Fig. 2, a) while other parameters of the depth profile remain constant. Dispersion curves of zero mode corresponding to 
different values of $L_{1}$ converge at both high and low frequencies and demonstrate the widest separation at intermediate frequencies (Fig. 2, c). At high frequencies the waves are concentrated rather close to coastline and they are not sensible to the position of shelf break. As we use the vertical wall at the coast, the dispersion of waves in our case will differ at high frequencies and their velocity will approach the asymptotic one $c=\left(g h_{1}\right)^{1 / 2}$ above the inclined bottom [11]. Indeed, the convergence of the dispersion curves for different $L_{1}$ at high frequencies is shown (Fig. 2). At low frequencies the wave propagates far beyond the boundaries of continental shelf and its phase velocity is close to the one of Kelvin wave.

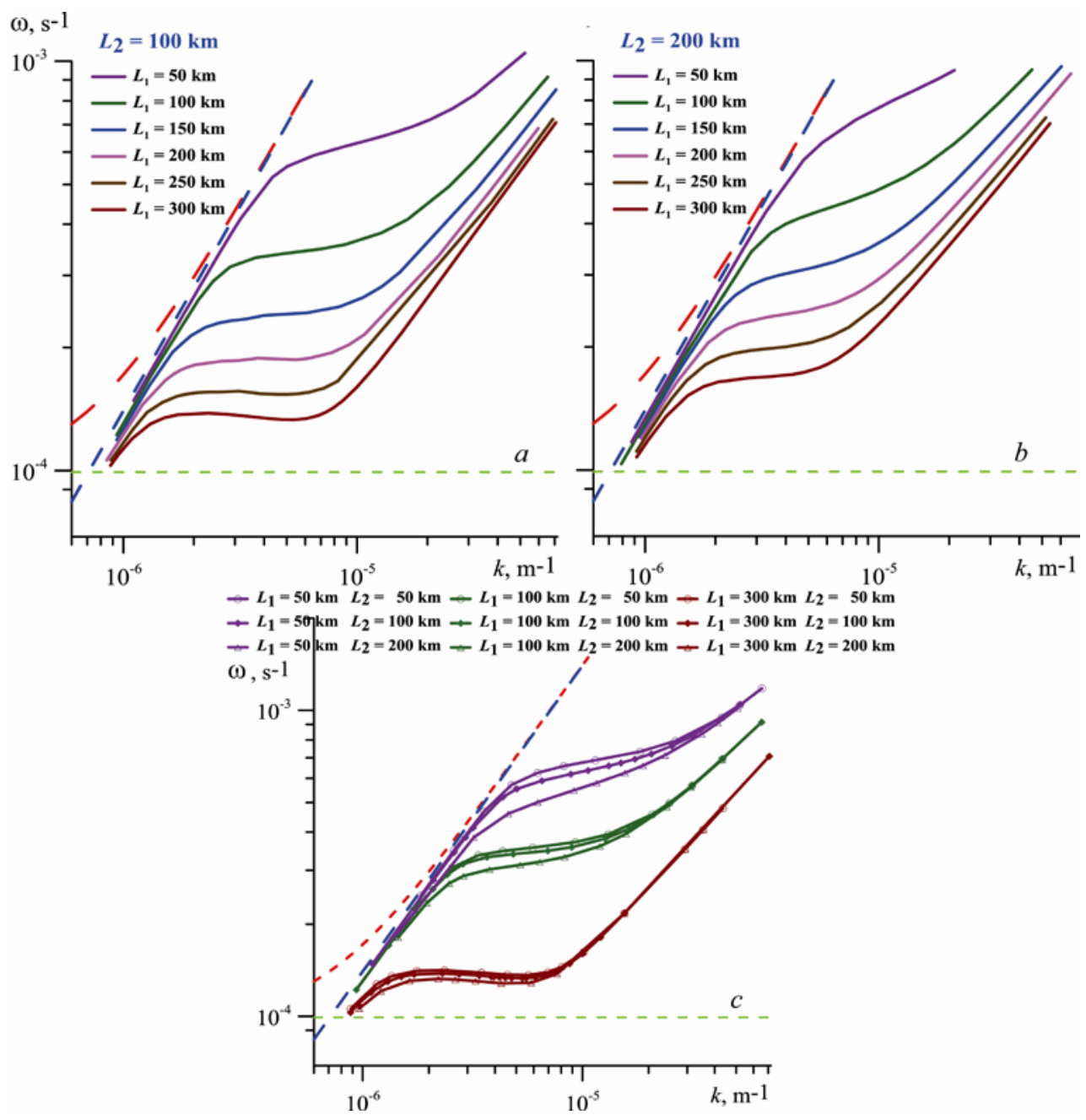

Fig. 2. Dispersion curves of the zero wave mode corresponding to different values of the shelf width. The dash lines confine the Poincaré wave continuum and the diurnal inertial frequency

The main regime has two asymptotic regimes corresponding to two different mechanisms of wave energy capture. At low frequencies it is similar to the Kelvin wave which manifests itself at vertical wall in the ocean of constant depth $h_{3}$ due to 
the Earth rotation and is described by dispersion relation $\omega=\left(g h_{3}\right)^{1 / 2} k$. At high frequencies its main regime reminds the zero one of the edge waves formed by long-wave refraction above the inclined bottom. At intermediate frequencies dispersion curves are horizontal under the condition of sufficiently wide shelf and their group velocity $C_{g}=\partial \omega / \partial k$ will be close to zero (Fig. 2). At these frequencies zero regime is a hybrid of Kelvin wave and the edge one [12].

Spatial-temporal characteristics of edge waves for real bottom profiles. The Black Sea bottom relief consists of the shelf area (smoothed area of continental submarine margin adjacent to the land and bounded by an edge with a sharp bend of the sea bottom surface defining the transition to the continental slope), continental slope (the sea bottom part characterized by relatively steep slope joining the shelf edge and relatively horizontal part of the bottom) and abyssal basin. Shelf zone of $100-160 \mathrm{~m}$ depth has the greatest width which exceeds $200 \mathrm{~km}$ in the north-western part of the sea. In other regions the shelf depth is usually less than $110 \mathrm{~m}$, and the width varies from $10-30 \mathrm{~km}$ to $2.5 \mathrm{~km}$ near the coast of Turkey.

The selection of the Anatolian coast region of the Black Sea is due to the presence of shelves where the presence of topographically modified Kelvin waves is assumed. In this region a complex bottom relief, formed as a result of activity of tectonic processes, takes place. The features of the Anatolian coast shelf region relief are represented in Fig. 3. The chosen bottom relief profiles also display the characteristic features of coastal area of the entire Black sea basin: the shelf width is $5-30 \mathrm{~km}$ (and just in certain regions it reaches $50 \mathrm{~km}$ and more), the continental slope begins from $100 \mathrm{~m}$ isobath. The slope geometry significantly varies in different regions of the sea but the width of the area of the maximum inclinations rarely exceeds $20 \mathrm{~km}$. The steepest slope is observed at 200-1000 m depths. Continental slope extends to $2000 \mathrm{~m}$ isobaths, although at $1000 \mathrm{~m}$ depth the bottom inclination decreases. In the open sea area the depth makes up 2000-2200 m.

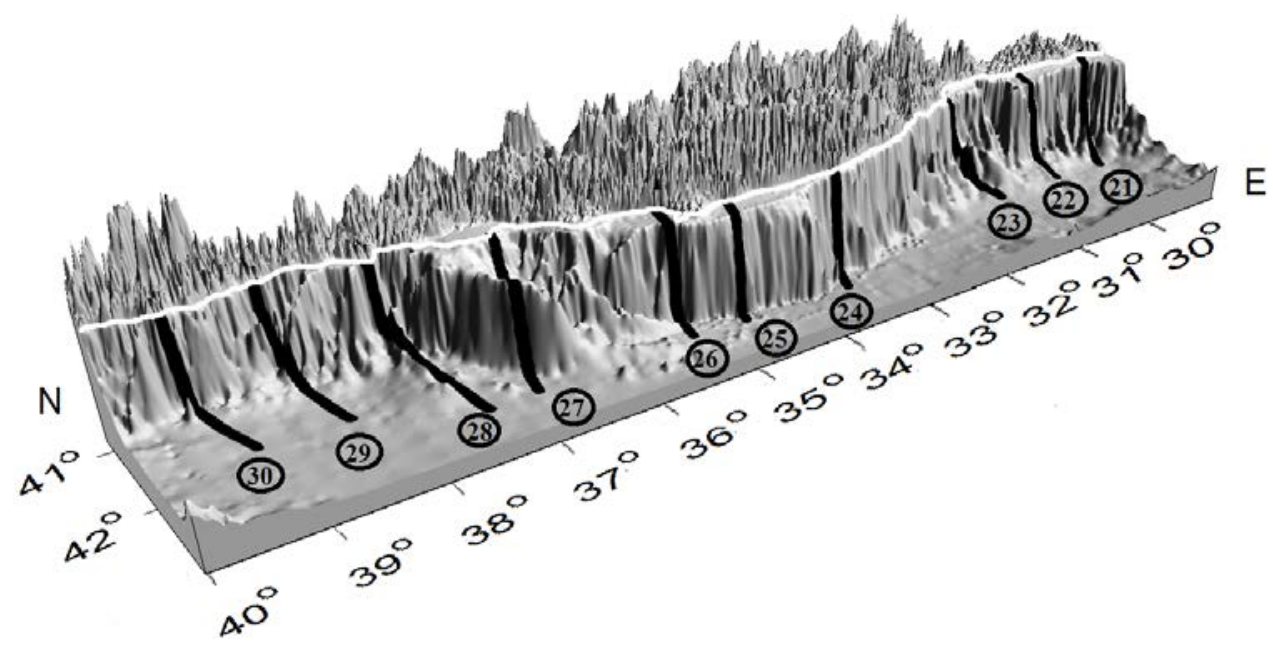

Fig. 3. Scheme of location of the bottom relief profiles 21-30 in the region of the Black Sea Anatolian coast 
Anatolian coast is characterized by a contrast shelf width. In the southeast at the foot of the Eastern Pontic Mountains (the Pontic shelf) its width does not exceed 3$4 \mathrm{~km}$. Near the Ordu it increases up to $12 \mathrm{~km}$, near the Calti Burnu cape - up to 16$20 \mathrm{~km}$ and reaches 25-30 km in the Sinop Bay near Ayanak and between Kandira and the Bosphorus. The depth of its outer edge runs along 110-130 km isobaths. From the Bosphorus to the Sinop the western Anatolian shelf has the maximum width of $25-30 \mathrm{~km}$. The narrowest shelf is located near Zonguldak and Karasu (less than 3-4 km), the shelf edge extends at 100-110 m depth [13]. For the Anatolian coast shelf, which is characterized by complex configuration of the coast and sharp drops of depths, topographic wave parameters are estimated at the frequencies which are close to the inertial ones. The possibility of existence of such waves above the sharp inclinations of the bottom was pointed out when calculating the barotropicbaroclinic instability of the Black Sea Rim Current [14].

For calculating the parameters of the edge waves the Black Sea bathymetry represented by the file of depths (URL: http://www.gebco.net) is used. General Bathymetric Chart of the Oceans (GEBCO) data are obtained by combining the depth bathymetric probings with the interpolation between the probing points and assimilation of satellite observations. The grid of these data is a continuous relief model of the ocean and the land with $0.5^{\circ}$ spatial resolution. In the file the data are represented in the following format: longitude with $0.008337676^{\circ} \mathrm{E}$ step, latitude with $0.008342022941^{\circ} \mathrm{N}$ step and the depth in meters. The profiles $21-30$ were chosen according to classic scheme of location of normal to the coast bottom relief profiles in the Black Sea shelf zone [15].

In Table 1, where the parameters of bottom relief profiles are given, for each of them the values of depth - near the coast $\left(h_{1}\right)$, slope $\left(h_{2}\right)$ and the open sea $\left(h_{3}\right)$ as well as the width values of the shelf $\left(L_{1}\right)$, continental slope $\left(L_{2}\right)$ and continental rise $\left(L_{3}\right)$ are given. Here the dimensionless coefficient of $\alpha=\partial H / \partial x$ profile inclination is also given.

Table 1

Parameters of the bottom relief profiles in the Anatolian coast region

\begin{tabular}{c|rrr|r|r|r|r|r|r}
\hline \multirow{2}{*}{ Profile } & \multicolumn{4}{|c|}{ Shelf } & \multicolumn{3}{c|}{ Slope } & \multicolumn{3}{c}{ Bottom } \\
\cline { 2 - 10 } & \multicolumn{1}{c}{$h_{1}, \mathrm{~m}$} & \multicolumn{1}{c}{$L_{1}, \mathrm{~km}$} & \multicolumn{1}{c}{$\alpha$} & $h_{2}, \mathrm{~m}$ & $L_{2}, \mathrm{~km}$ & $\alpha$ & $h_{3}, \mathrm{~m}$ & $L_{3}, \mathrm{~km}$ & $\alpha$ \\
\hline 21 & 1 & 2.1 & 14.9 & 156 & 18.7 & 108.3 & 1884 & 53.1 & 2.7 \\
22 & 12 & 2.1 & 51.3 & 181 & 30.5 & 67.6 & 1833 & 53.8 & 4.4 \\
23 & 15 & 3.7 & 28.3 & 115 & 65.4 & 31.6 & 1915 & 46.6 & 5.2 \\
24 & 8 & 6.7 & 25.4 & 162 & 66.9 & 43.9 & 1959 & 24.6 & 5.3 \\
25 & 3 & 25.0 & 5.3 & 109 & 18.5 & 178.7 & 2188 & 17.1 & 4.9 \\
26 & 17 & 20.6 & 5.5 & 110 & 16.7 & 116.9 & 1961 & 10.3 & 15.8 \\
27 & 27 & 3.9 & 31.8 & 144 & 17.0 & 118.7 & 2064 & 19.2 & 14.1 \\
28 & 10 & 18.2 & 7.6 & 111 & 28.6 & 73.8 & 1864 & 26.2 & 7.1 \\
29 & 1 & 18.4 & 11.2 & 165 & 20.0 & 94.6 & 1834 & 28.3 & 6.4 \\
30 & 1 & 2.1 & 8.9 & 156 & 18.7 & 56.4 & 1884 & 53.1 & 4.9 \\
\hline
\end{tabular}




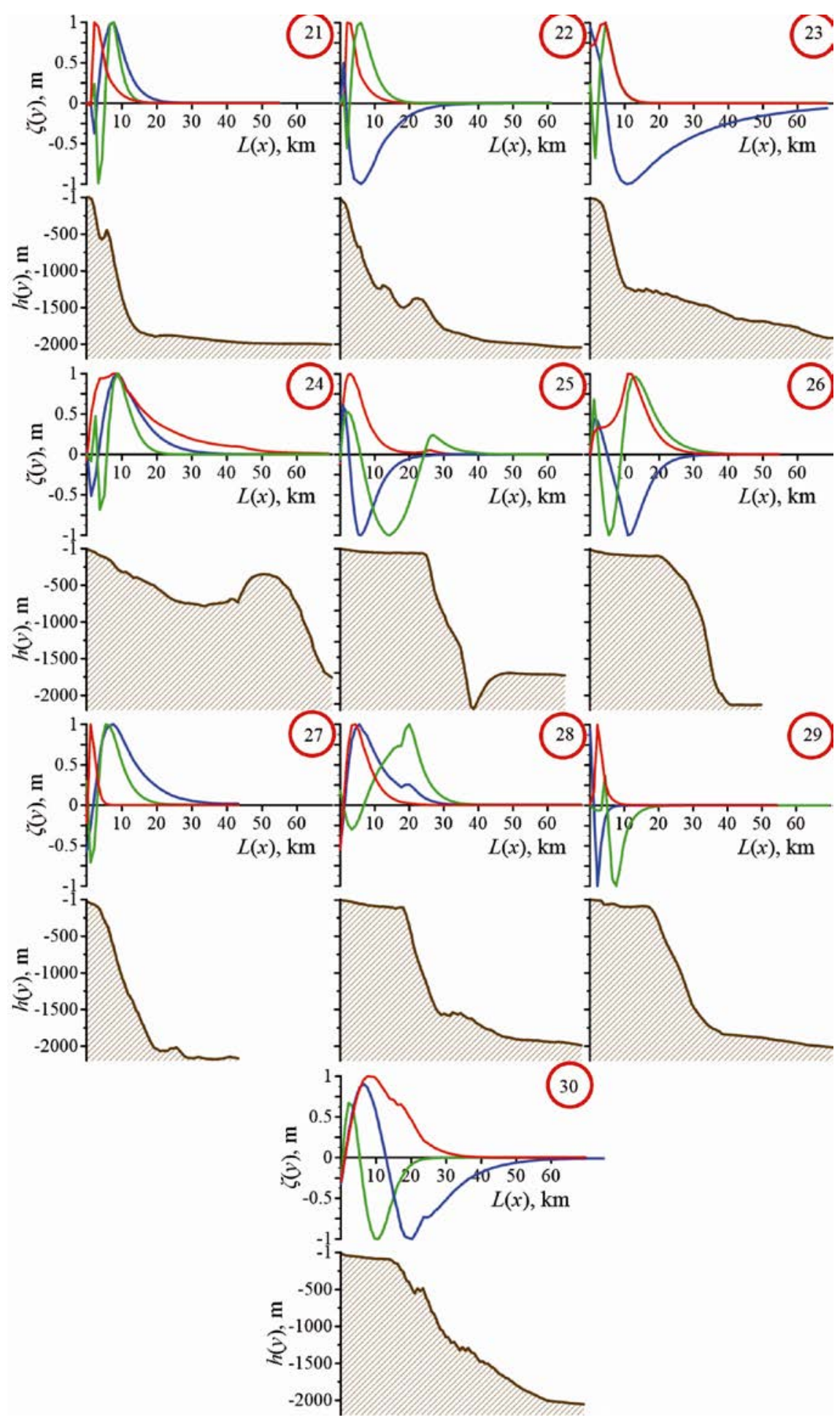

Fig. 4. The bottom relief profiles 21-30 and the amplitude functions $\zeta(y)$ of the zero (red curves), the first (blue curves) and the second (green curves) modes in the Anatolian coast region 
The Anatolian coast feature is a submarine terrace (profiles 23 and 24) at $500 \mathrm{~m}$ depth. Profiles 25, 26 and 29 have the greatest width of the shelf 18.4$25 \mathrm{~km}$. A sharp transition to the continental slope (where the maximum $\alpha=51.3$ ) is observed at the profile 22. The profiles 21-24 situated in the eastern part of the Anatolian coast and the profile 30 near the Bosphorus entrance are the most specific ones. Here the shelf is practically absent ( $L_{1}$ is $\left.2.1-6.7 \mathrm{~km}\right)$, coastal bank is narrow, the bottom inclinations are small, $h(y)$ profile is close to the quasi-linear one (Fig. 3, 4).

As it can be seen in Fig. 4, spatial resolution of shelf waves is determined by the shelf width. The points in which $\zeta(y)$ reaches the maximum correspond the coastline and the shelf edge, nodal line is close to the shelf center. The main features of zero mode wave profile are determined by the shelf dimensions. The role of the slope geometry increases for the second mode waves. In this case, the wave length and phase rate grow at both increase of shelf width and slope width. The first nodal line $\zeta$ of the second mode waves is located above the shelf, the second on - above the continental slope near the shelf edge. In the bottom profiles at a shelf width comparable or smaller than the slope one the maximum $\zeta$ is observed near the coast. In the case when the shelf width exceeds the one of the slope the maximum $\zeta$ shifts from the coastline. As a result, the second mode waves are more sensible to the changes of the shelf geometry in comparison with the first mode waves.

The parameters of the lowest modes of shelf waves obtained on the basis of analytic solution are represented in Table 2.

Table 2

Location of the absolute maximums $\left(y_{\max }\right)$ of the shelf waves' amplitudes and the attenuation points' $\left(y_{0}\right)$ coordinates in the Anatolian coast region

\begin{tabular}{c|rrr|r|r|l}
\hline \multirow{2}{*}{ Profile } & \multicolumn{5}{|c|}{$y_{\max }, \mathrm{km}$} & \multicolumn{3}{c}{$y_{0}, \mathrm{~km}$} \\
\cline { 2 - 7 } & \multicolumn{7}{|c}{ zero } & \multicolumn{1}{c|}{ first } & second & \multicolumn{1}{c}{ zero } & \multicolumn{1}{c}{ first } & second \\
\cline { 2 - 7 } & 2.19 & 7.69 & 7.69 & 17.582 & 25.28 & 17.58 \\
21 & 2.00 & 8.00 & 6.00 & 18.00 & 35.00 & 22.00 \\
22 & 4.47 & 10.44 & 4.47 & 16.41 & 107.42 & 16.42 \\
23 & 8.79 & 3.77 & 6.28 & 71.56 & 38.92 & 23.852 \\
24 & 3.00 & 6.00 & 14.25 & 31.50 & 27.00 & 43.50 \\
25 & 10.94 & 10.94 & 5.47 & 33.91 & 32.82 & 40.48 \\
26 & 1.08 & 7.58 & 5.411 & 6.49 & 43.28 & 23.81 \\
27 & 4.44 & 5.55 & 19.97 & 23.29 & 33.28 & 38.83 \\
28 & 3.26 & 4.35 & 7.60 & 10.86 & 7.60 & 20.64 \\
29 & 7.50 & 10.72 & 20.36 & 38.58 & 25.72 & 68.59 \\
30 & \multicolumn{7}{c}{}
\end{tabular}

In Fig. 5 on the left the graphs, in which we note the distance from the coast to the point where the maximum wave amplitude is reached, are given. Here (Fig. 5, on the right) the coordinates of attenuation point $\zeta(y)$ up to the value which does not exceed $1 \mathrm{~cm}$ are also shown. The maximums near the shore and above the shelf 
edge are comparable, although if $L_{1}>L_{2}$, then the maximum is marked above the shelf edge, if $L_{1} \leq L_{2}-$ near the coast.
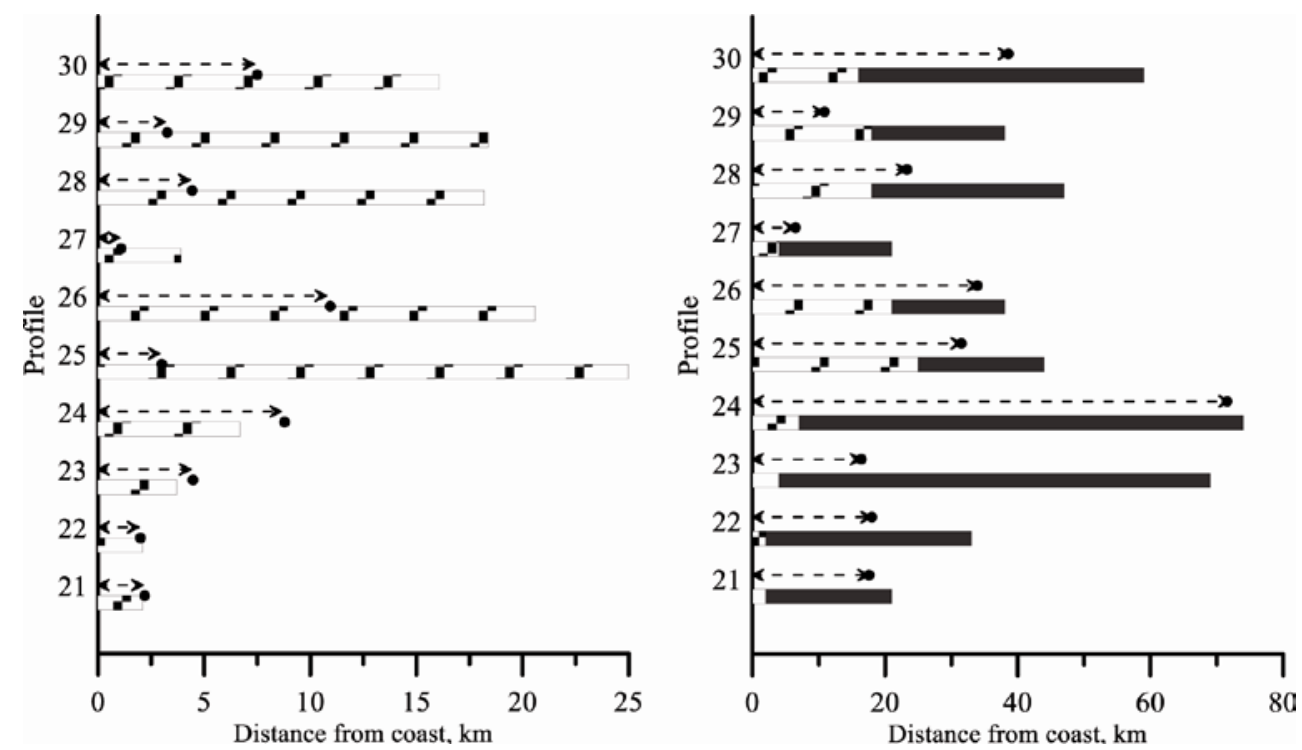

Fig. 5. Distances from the coast to the maximum (to the left) and attenuation (to the right) points of the amplitude of the shelf waves' zero mode on profiles 21-30. The dash line corresponds to the shelf length, the solid one - to the continental slope dimension

The continental slope width increase results in slower wave attenuation towards the open sea, however the position of $\zeta_{\max }$ point changes insignificantly. At rather wide slope (profile 23) its distance from the coast is $4.7 \mathrm{~km}$, at more narrow one (profile 28) - $4.4 \mathrm{~km}$, although the slope width decreased from 65.4 to $18.2 \mathrm{~km}$. The radius of capture of the first mode shelf waves, which is not equal to width of variable depths zone, is determined by the shelf width. At the bottom profiles with wide and gentle slope $(21-23,26,27,30)$ that significantly exceeds the shelf width, wave attenuation towards the open sea occurs above the center of the slope. Conversely, at the profiles where $L_{1}>L_{2}$ the capture radius is significantly wider than the zone of variable depths. The length of the first mode shelf wave grows faster at the shelf width increase than at the slope width increase.

For profile 25 (Table 3) in the area of Ince Burnu cape (the northernmost point of the Anatolian coast) the longest period of shelf waves (23, $24 \mathrm{~h}$ ) was obtained. The duration of long wave periods at other profiles is approximately $6 \mathrm{~h}$ (profiles $26,29,30)$ and $1-3 \mathrm{~h}$ (profiles 21-25, 28). At the widest shelf (25 km) in profile 25 the length of zero mode wave is $5.35 \mathrm{~km}$, in profile 22 at the shelf width of $2.1 \mathrm{~km}$ (11.9 times smaller than in profile 25) the length of the first mode wave is 2.95 times smaller $(1.81 \mathrm{~km})$. 
Spatial-temporal parameters of zero mode shelf waves in the Anatolian coast region

\begin{tabular}{|c|c|c|c|c|c|}
\hline Profile & Wave number & Wave length & Frequency & Period & Velocity \\
\hline 21 & $\begin{array}{c}3.05 \cdot 10^{-6}- \\
9.38 \cdot 10^{-5}\end{array}$ & $67-2058$ & $\begin{array}{c}3.82 \cdot 10^{-4}- \\
1.36 \cdot 10^{-3}\end{array}$ & $1.28-4.57$ & $14.5-125.0$ \\
\hline 22 & $\begin{array}{c}8.51 \cdot 10^{-6}- \\
1.29 \cdot 10^{-4}\end{array}$ & 49-738 & $\begin{array}{c}1.19 \cdot 10^{-3}- \\
5.18 \cdot 10^{-3}\end{array}$ & $0.34-1.47$ & $40.0-140.0$ \\
\hline 23 & $\begin{array}{c}4.94 \cdot 10^{-6}- \\
1.10 \cdot 10^{-4}\end{array}$ & $57-1271$ & $\begin{array}{c}6.87 \cdot 10^{-4}- \\
7.69 \cdot 10^{-3}\end{array}$ & $0.23-2.54$ & 70.0-138.9 \\
\hline 24 & $\begin{array}{c}3.97 \cdot 10^{-6}- \\
2.17 \cdot 10^{-4}\end{array}$ & 29-1582 & $\begin{array}{c}5.44 \cdot 10^{-4}- \\
6.51 \cdot 10^{-3}\end{array}$ & $0.27-3.21$ & $30.0-137.0$ \\
\hline 25 & $\begin{array}{c}5.65 \cdot 10^{-6}- \\
1.46 \cdot 10^{-4}\end{array}$ & $43-1112$ & $\begin{array}{c}7.83 \cdot 10^{-4}- \\
2.93 \cdot 10^{-3}\end{array}$ & $0.60-23.2$ & 20.0-138.5 \\
\hline 26 & $\begin{array}{c}5.49 \cdot 10^{-6}- \\
2.22 \cdot 10^{-4}\end{array}$ & $28-1145$ & $\begin{array}{c}7.57 \cdot 10^{-4}- \\
5.54 \cdot 10^{-3}\end{array}$ & $0.32-2.31$ & 25.0-138.0 \\
\hline 27 & $\begin{array}{c}6.24 \cdot 10^{-6}- \\
1.48 \cdot 10^{-4}\end{array}$ & $43-1007$ & $\begin{array}{c}8.71 \cdot 10^{-4}- \\
8.86 \cdot 10^{-3}\end{array}$ & $0.20-2.00$ & 60.0-139.55 \\
\hline 28 & $\begin{array}{c}3.03 \cdot 10^{-6}- \\
2.08 \cdot 10^{-4}\end{array}$ & $30-2076$ & $\begin{array}{c}4.19 \cdot 10^{-4}- \\
4.58 \cdot 10^{-3}\end{array}$ & $0.38-4.16$ & 22.0-138.6 \\
\hline 29 & $\begin{array}{c}4.48 \cdot 10^{-6}- \\
2.09 \cdot 10^{-4}\end{array}$ & $30-1403$ & $\begin{array}{c}6.20 \cdot 10^{-4}- \\
3.76 \cdot 10^{-3}\end{array}$ & $0.46-2.81$ & $18.0-138.5$ \\
\hline 30 & $\begin{array}{c}6.93 \cdot 10^{-6}- \\
3.07 \cdot 10^{-4}\end{array}$ & 20-907 & $\begin{array}{c}9.56 \cdot 10^{-4}- \\
7.06 \cdot 10^{-3}\end{array}$ & $0.25-1.82$ & 23.0-138.0 \\
\hline
\end{tabular}

\section{Analysis of the modeling results}

Numerical model and its configuration. For the numerical experiments the regional model of the Black and Azov Seas circulation developed in the Institute of Numerical Mathematics (INM) RAS is used. 3D model is based on a system of primitive equations of the ocean hydrodynamics written in incompressibility, hydrostatics and Boussinesq approximations. Dimensionless variable $\sigma$ is used as vertical axis in the model. Ocean dynamics equations are written in symmetrized form [16]. Application of splitting methods to physical processes and spatial coordinates in the model substantially increases the economics of calculations [17].

Coordinates of computational area approximating the water are area of the Black

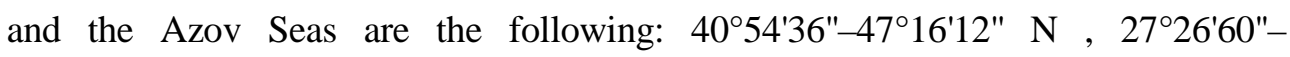
$41^{\circ} 45^{\prime} 00^{\prime \prime} \mathrm{E}$, spatial resolution of the grid is $0^{\circ} 2{ }^{\prime} 24^{\prime \prime} \times 0^{\circ} 3^{\prime}$ in latitude and longitude, respectively. $40 \sigma$-levels non-uniformly distributed over the depth are set in vertical direction. Computational time step is $5 \mathrm{~min}$. In order to calculate the climatic atmospheric effect the data of Coordinated Ocean-ice Reference Experiments (CORE) [18] are used in INM model. Their spatial resolution is non-uniform in latitude and makes up $1.825^{\circ}$ in longitude. The results of the model validation with the applied climatic effect are represented in [19]. 
Integration of the motion equations in the experiment is performed from zero initial conditions during two years (730 days). The first climatic year and winter months of the second one are used to "disperse" the model. For the analysis 10 months of the second year (from March) with 45 min data release discreteness are taken. The data on the velocity of surface currents and sea level were saved and analyzed. For 10 profiles 21-30, in the Anatolian coast area the datasets have been selected (Fig. 6). At each section 5 stations uniformly spaced along the profile and the grid are selected.

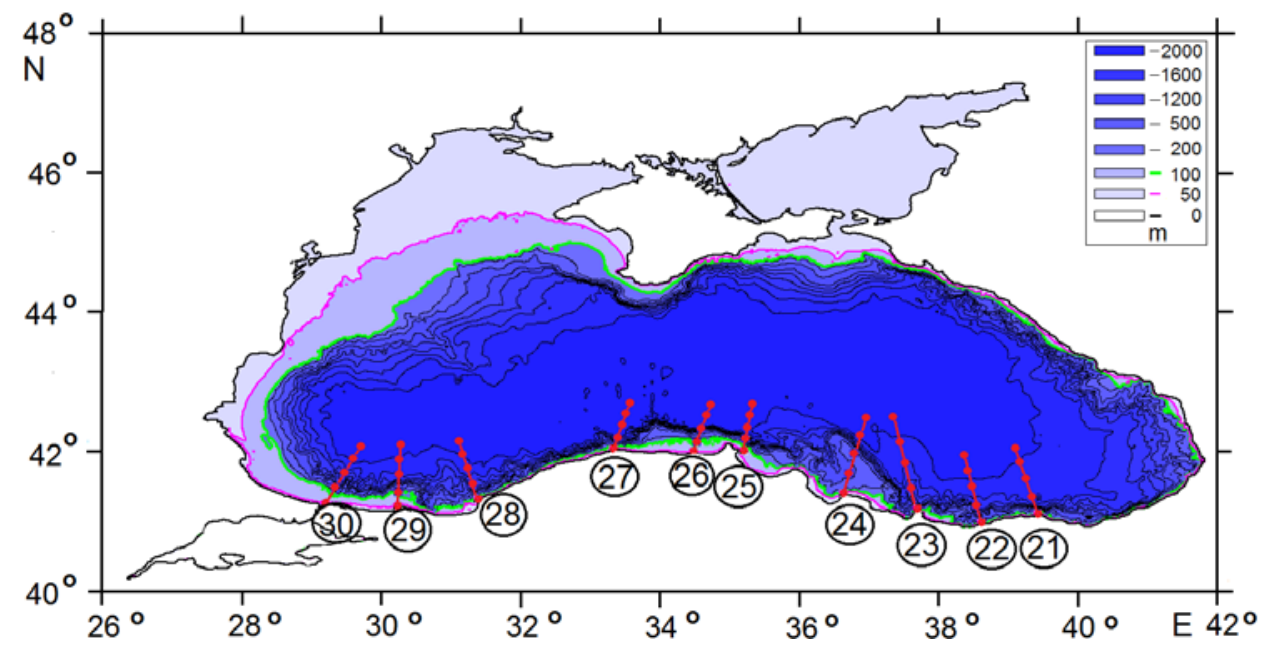

Fig. 6. The bottom relief of the area intended for numerical experiments using the model developed in the Institute of Numerical Mathematics. The points on the profiles 21-30 denote the stations where the sea level and current velocity variations are analyzed. Red line corresponds to the $50 \mathrm{~m}$ isohypse, green - to the $100 \mathrm{~m}$ one

Analysis of sea level spectra. According to the data of climatic calculation for 50 stations located at 21-30 profiles of the Anatolian coast, the spectra of sea level fluctuation amplitudes were calculated using fast Fourier transformation [20]. We used a spectral window with the selected length $N=7200$ h (300 day) and a half overlap. Therefore, spectral resolution is $\Delta f \approx 0.0033$ cycle/day. In Fig. 7 the spectra of sea level fluctuation amplitudes for the stations located above the shelf and in the deep part (see Table 1) with 95\% confidence interval are shown. The frequencies corresponding to 12- and 24-hour periods are shown by vertical lines.

It can be seen that at all the spectra 6-, 12- and 24-hour peaks stand out. At deepwater stations 12-hour peak is manifested brighter. At semidiurnal period, sea level fluctuations for all the spectra have the maximum amplitude among all mesoscale fluctuations. It also exceeds the spectral amplitude of inertial fluctuations. 


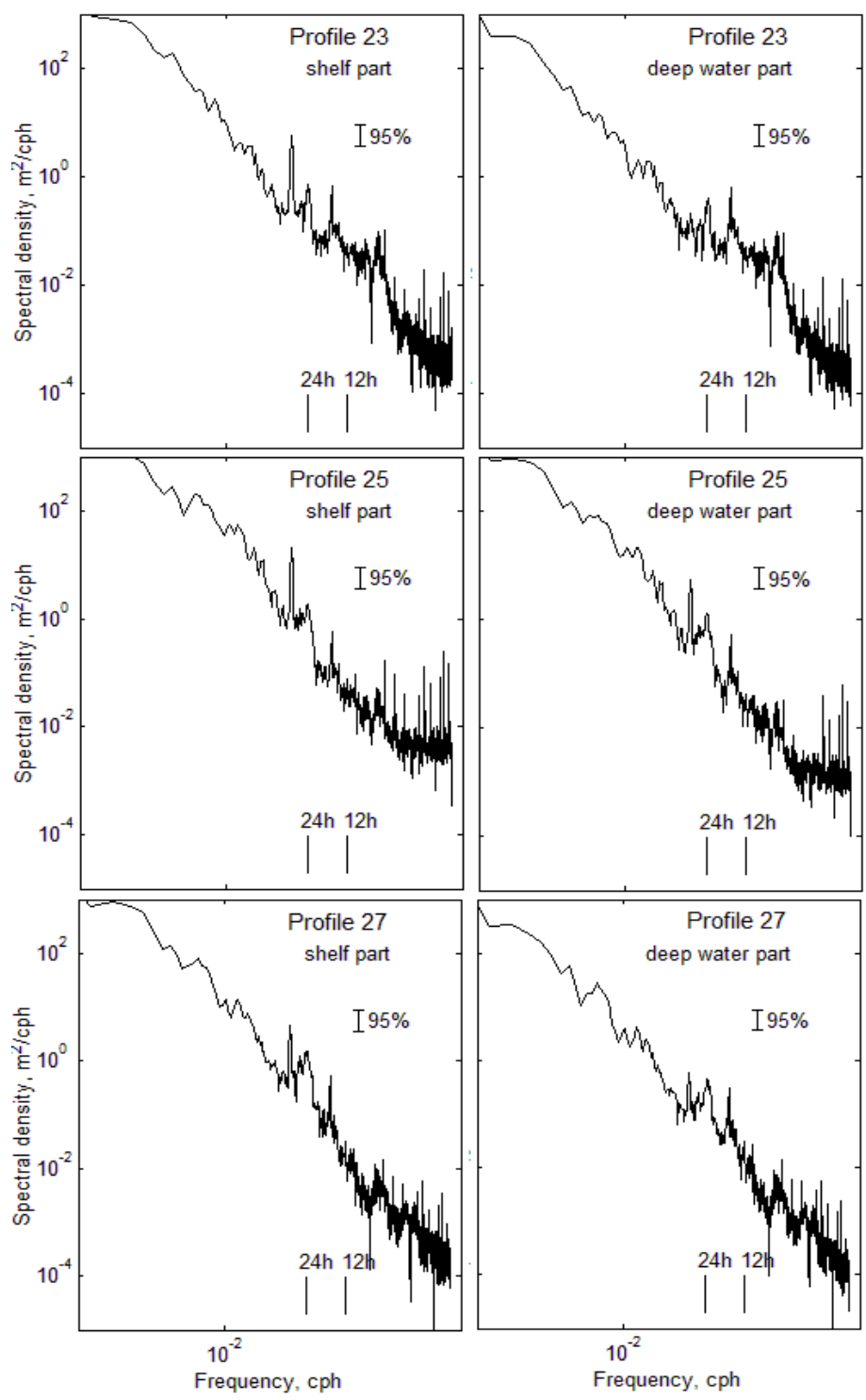

Fig. 7. Spectral density of the level amplitudes ( $\left.\mathrm{m}^{2} / \mathrm{cycle} / \mathrm{h}\right)$ ) for profiles 23,25 and 27 at the stations located in the shelf region (to the left) and in the deep part of the sea (to the right) based on the results of modeling in course of 10 months (the $2^{\text {nd }}$ year of calculations)

\section{Conclusion}

We are to formulate the main results of the work. Zero mode of trapped waves is a hybrid wave that combines the features of Kelvin and Stokes waves in a certain frequency area when both topographic and rotational effects are sufficient. At rather wide shelf these waves exist within the semidiurnal frequencies and their group velocity can become a zero one. In the experiments with real topography it is obtained that the profile of shelf waves is determined by the shelf width and, to a lesser extent, by the continental slope width. The maximum amplitude is recorded 
near the shelf edge. Continental slope width has practically no effect on the amplitude of shelf waves.

\section{REFERENCES}

1. Efimov, V.V. Kulikov, E.A., Rabinovich, A.B. and Fine, I.V., 1985. Volny v Pogranichnykh Oblastyakh Okeana [Ocean Boundary Waves]. Leningrad: Gidrometeoizdat, 280 p. (in Russian).

2. LeBlond, P.H. and Mysak, L.A., 1978. Waves in the Ocean. Amsterdam: Elsevier, 617 p.

3. Mysak, L.A., 1980. Recent Advances in Shelf Wave Dynamics. Reviews of Geophysics, [e-journal] 18(1), pp. 211-241. doi:10.1029/RG018i001p00211

4. Palma, E.D., Matano, R.P. and Piola, A.R., 2004. A Numerical Study of the Southwestern Atlantic Shelf Circulation: Barotropic Response to Tidal and Wind Forcing. Journal of Geophysical Research, [e-journal] 109(C8), pp. C08014. doi:10.1029/2004JC002315

5. Munk, W., Snodgrass, F. and Wimbush, M., 1970. Tides off-shore: Transition from California Coastal to Deep-Sea Waters. Geophysics Fluid Dynamics, [e-journal] 1(1-2), pp. 161-235. doi:10.1080/03091927009365772

6. Gill, A.E., 1986. Atmosphere-Ocean Dynamics. Cambridge: Academic Press, 662 p.

7. Ke, Z. and Yankovsky, A.E., 2010. The Hybrid Kelvin-Edge Wave and its Role in Tidal Dynamics. Journal of Physical Oceanography, [e-journal] 40(12), pp. 2757-2767. doi:10.1175/2010JPO4430.1

8. Pedlosky, J., 2003. Waves in the Ocean and Atmosphere: Introduction to Wave Dynamics. Berlin: Springer, $260 \mathrm{p}$.

9. Yankovsky, A.E. and Zhang, T., 2017. Scattering of a Semidiurnal Barotropic Kelvin Wave into Internal Waves over Wide Continental Shelves. Journal of Physical Oceanography, [e-journal] 47(10), pp. 2545-2562. doi:10.1175/JPO-D-16-0284.1

10. Huthnance, J.M., 1975. On Trapped Waves over a Continental Shelf. Journal of Fluid Mechanics, [e-journal] 69(4), pp. 689-704. doi:10.1017/S0022112075001632

11. Kurkin, A. and Pelinovsky, E., 2002. Focusing of Edge Waves above a Sloping Beach. European Journal of Mechanics-B/Fluids, [e-journal] 21(5), pp. 561-577. doi:10.1016/S09977546(02)01201-3

12. Yankovsky, A.E., 2009. Large-Scale Edge Waves Generated by Hurricane Landfall. Journal of Geophysical Research, [e-journal] 114, pp. 03-014. doi:10.1029/2008JC005113

13. Ignatov, E.I., 2010. Sovremennye Predstavleniya o Rel'efe Beregov i Dna Chernogo Morya [Current Concepts of the Coastal and Bottom Relief of the Black Sea]. Vestnik Moskovskogo Universiteta, Seriya Geografiya, [e-journal] (1), pp. 56-63 (in Russian).

14. Blatov, A.S., Bulgakov, N.P., Ivanov, V.A. Kosarev, A.N. and Tuzhilkin, V.S., 1984. Izmenchivost' Gidrofizicheskikh Poley Chernogo Morya [Variability of Hydrophysical Fields of the Black Sea]. Leningrad: Gidrometeoizdat, 240 p. (in Russian).

15. Blatov, A.S. and Ivanov, V.A., 1992. Gidrologiya i Gidrodinamika Shel'fovoy Zony Chernogo Morya (na Primere Yuzhnogo Berega Kryma) [Hydrology and Hydrodynamics of the Shelf Zone of the Black Sea (on the Example of the Southern Coast of Crimea)]. Kiev: Naukova Dumka, 224 p. (in Russian).

16. Zalesny, V.B., Gusev, A.V. and Moshonkin, S.N., 2013. Chislennaya Model Gidrodinamiki Chernogo i Azovskogo Morej s Variacionnoj Inicializaciej Temperatury i Solenosti [Numerical Model of the Hydrodynamics of the Black Sea and the Sea of Azov with Variational Initialization of Temperature and Salinity]. Izvestiya. Fizika Atmosfery i Okeana, [e-journal] 49(6), pp. 642-658. https://doi.org/10.1134/S0001433813060133

17. Marchuk, G.I., 2009. Metody Vychislitel'noy Matematiki [Methods of Computational Mathematics]. Saint Petersburg: Lan', 608 p. (in Russian)

18. Geophysiacl Fluid Dynamics Labaratory, 2018. GFDL'S Data Portal. [online] Available at: http://data1.gfdl.noaa.gov/ [Accessed: 20 January 2018]. 
19. Lukyanova, A.N., Bagaev, A.V., Ivanov, V.A. and Zalesny, V.B., 2017. Sub-Inertial Oscillations in the Black Sea Generated by the Semidiurnal Tidal Potential. Izvestiya, Atmospheric and Oceanic Physics, [e-journal] 53(6), pp. 624-631. https://doi.org/10.1134/S000143381706007X

20. Emery, W.J. and Thomson, R.E., 2001. Data Analysis Methods in Physical Oceanography: 2-nd Edition. [e-book] Elsevier Science, 654 p. doi:10.1016/B978-0-444-50756-3.X5000-X

About the authors:

Vitaliy I. Ivanov - the Head of Coastal Research Scientific Direction, FSBSI MHI (2 Kapitanskaya Str., Sevastopol, 299011, Russian Federation), Academician of RAS, Dr.Sci. (Phys.Math.), professor, ResearcherID: I-7436-2013, vaivanov@mhi-ras.ru

Tat'yana Ya. Shul'ga - Senior Research Associate, Shelf Hydrophysics Department, FSBSI MHI (2 Kapitanskaya Str., Sevastopol, 299011, Russian Federation), Ph.D. (Phys.-Math.), ORCID ID: 0000-0002-7873-6697, ResearcherID: P-9894-2015, SPIN-code: 2423-6440, shulgaty@mail.ru

Tat'yana V. Plastun - Junior Research Associate, Oceanography Department, FSBSI MHI (2 Kapitanskaya Str., Sevastopol, 299011, Russian Federation), SPIN-code: 7165-6187, ptv63@inbox.ru

Irina A. Svishcheva - Leading Engeneer-Programmer, Shelf Hydrophysics Department, FSBSI MHI (2 Kapitanskaya Str., Sevastopol, 299011, Russian Federation), ORCID ID: 0000-0003-15013720, ResearcherID: M-4451-2018, svishcheva.iryna@gmail.com

Contribution of the co-authors:

Vitaliy I. Ivanov - general scientific supervision, development and scientific substantiation of the research concept, problem statement and formulation, formulation of conclusions, editing and completing the article text.

Tat'yana Ya. Shul'ga - analysis of materials in domestic and foreign sources on the research methods, the concept study and development, research task statement, development of methods and carrying out the experimental studies, qualitative and quantitative analysis of the study results and preparation of initial conclusions, preparation of the article text.

Tat'yana V. Plastun - collection of available materials on the research theme, development and debugging of the data processing computer program, formalized data analysis, construction of graphs and drawings, editing and completing the article text.

Irina A. Svishcheva - formalized data analysis, data processing by a computer program, visualization of data in the text, construction of graphs and drawings.

All the authors have read and approved the final manuscript.

The authors declare that they have no conflict of interest. 